\title{
Fractures around the Pelvis, Pelvic Rim \& Acetabulum in the Elderly: Report on 54 Cases
}

\section{Peter Reynders-Frederix ${ }^{1}$, Cristina Reynders-Frederix ${ }^{2}$, Freddy Mboti ${ }^{1}$, Dragos Schiopu ${ }^{1}$, Tamas Illes ${ }^{1,3}$}

\author{
${ }^{1}$ Section Orthopedic Surgery, Department of General Surgery, Campus Brugmann, University Hospitals Brussels, \\ Brussels, Belgium \\ ${ }^{2}$ Section Physiotherapy \& Rehabilitation, Department of Internal Medicine, Campus Saint Pierre, University Hospitals Brussels, \\ Brussels, Belgium \\ ${ }^{3}$ Department of Orthopaedic Surgery and Traumatology, Odense University Hospital and Institute of Clinical Research, University \\ of Southern Denmark, Denmark
}

Email: ${ }^{\star}$ reynders52@hotmail.com

How to cite this paper: Reynders-Frederix, P., Reynders-Frederix, C., Mboti, F., Schiopu, D. and Illes, T. (2020) Fractures around the Pelvis, Pelvic Rim \& Acetabulum in the Elderly: Report on 54 Cases. Open Journal of Orthopedics, 10, 54-66.

https://doi.org/10.4236/ojo.2020.103008

Received: January 22, 2020

Accepted: March 3, 2020

Published: March 6, 2020

Copyright (c) 2020 by author(s) and Scientific Research Publishing Inc. This work is licensed under the Creative Commons Attribution International License (CC BY 4.0).

http://creativecommons.org/licenses/by/4.0/

\section{Open Access}

\begin{abstract}
The authors report on 34 patients with a pelvic rim disruption who were treated with percutaneous $7.3 \mathrm{~mm}$ screws. This technique is less invasive and gives immediate comfort. Screws were placed with conventional fluoroscopic assistance. In four cases, the screw tip was protruding out of the pelvic bone, two malposition screws were in the back, and two were in the front of the pelvic ring. A revision was needed in one case. We also report on 20 elderly patients with a fracture dislocation of the hip that ran into the pelvis. Eight of them were anteromedial dislocations, and the rest were central dislocations of the femoral head. In the group of anteromedial fracture dislocations, the results were excellent, with an open reduction and internal fixation (ORIF) achieved through a retroperitoneal approach. In the subgroup of central fracture dislocations, we performed the same type of osteosynthesis via the retroperitoneal approach. However, we obtained an excellent result for only two cases. We have a couple of results. First, a percutaneous screw fixation for pelvic fractures with fluoroscopic guidance gives excellent results in most cases. Second, central fracture dislocations of the hip perform poorly after osteosynthesis via the retroperitoneal approach. These fractures probably should be offered acute or delayed total hip arthroplasty (THA).
\end{abstract}

\section{Keywords}

Geriatric Fractures, Pelvic Fractures, Acetabular Fractures, MIPO Techniques 


\section{Introduction}

From 1970-1997, the incidence of osteoporotic fractures of the pelvis increased by $460 \%$ [1]. The impact of these fractures is substantial and underestimated [2]

[3] [4]. There is reported slow healing of these fractures with non-operative treatment, with a mortality rate at one year of $20 \%$ and a return to the same functional level at one year of only $16 \%$ [5] [6]. In pelvic ring fractures, the posterior fracture of the sacral wing is often not seen on plain radiographs, making CT evaluation necessary for a complete diagnosis. Ricci and Gerich [7] showed through a theoretical analysis using an elaborated finite element model of a pelvis that the stresses at the sacral wing increase dramatically after interruption of the pubic rami. The work of Ricci and Gerich can explain why we often see fatigue fractures in the back of the pelvic ring together with fractures of the pubic area. Pain is predominant after pelvic ring fractures, making nursing with simple transfers out of bed difficult. In the protrusion type of acetabular fractures, the incapacity of the elderly patient is more pronounced. In these frail patients, the combination of pain, blood loss, and oftentimes being bedridden can be fatal in the early onset of the illness. When the patients cannot sit upright, pneumonia and or urinary infections can lead to early death. Recent reports favour early internal fixation as the preferred treatment for most of the displaced fractures of the pelvis and acetabulum. Concerning fatigue fractures of the pelvic ring, there is a consensus about fixing these fractures in a minimally invasive way. Percutaneous fixation by cannulated screws offers a definite advantage. There is some awareness among surgeons about the feasibility of this technique, favouring expensive navigation tools instead. However, for fracture dislocations of the hip joint, be it central or anterior, there exists no treatment consensus.

In our study, there was a clear tendency of good access to the anterior pelvic ring fracture by percutaneously screw fixation under image intensifier control. Anterior fracture dislocation of the hip joint was amenable by anterior column plate fixation via an extensive retroperitoneal approach.

In central fracture dislocation of the acetabulum, we could not retain the hip joint after open reduction and plate osteosynthesis. Even the liberal use of the quadrilateral buttress plates could not prevent the gradual secondary displacement of the hip in this subgroup.

\section{Methods \& Patients}

In this study we treated 54 out of 122 patients with pelvic ring and acetabular fractures postoperatively.

Patients' demographics are resumed in Figure 1.

Permission of the local ethical comity was granted under the number CE2019/141.

All patients with displaced fractures of the pelvis and acetabulum were selected for reduction and fixation techniques. Only patients who were refused by the anaesthetist because of severe co-morbidities were excluded for operative treatment. Also patients who were too much impaired to consent for operative treatment were excluded. 


\begin{tabular}{|c|c|c|c|c|c|c|c|}
\hline & Number & Acetabulum & Pelvis & Treatment & Complications & Results & Co-Morbidities \\
\hline 1 & 201032713 & $\mathrm{AM}$ & & Plate & none & Excellent & $\mathrm{HA}, \mathrm{TAB}$ \\
\hline 2 & 200899956 & & A\&P & Screw fixation & DVT, MP-P & Good & None \\
\hline 3 & 200437968 & & A & Screw fixation & none & Moderate & DIAB, HA, \\
\hline 4 & 200138099 & & $\mathrm{~A} \& \mathrm{P}$ & Screw fixation & none & Moderate & DIAB, HA, UI \\
\hline 5 & 201023641 & & A\&P & Screw fixation & none & Moderate & TIA, $\mathrm{CaBr}$, \\
\hline 6 & 201022170 & & $\mathrm{P}$ & Screw fixation & none & Good & None \\
\hline 7 & 200346830 & & $\mathrm{~A} \& \mathrm{P}$ & Screw fixation & MP-P & Excellent & Tox. \\
\hline 8 & 201031710 & $\mathrm{AM}$ & & Plate & none & Good & HA, TAB, DIAB \\
\hline 9 & 200015122 & & $\mathrm{~A}$ & Screw fixation & none & Excellent & HA, PY, Eth. \\
\hline 10 & 200088069 & & $\mathrm{~A}$ & Screw fixation & none & Excellent & PY \\
\hline 11 & 200022640 & & $\mathrm{~A}$ & Screw fixation & none & Excellent & HA, PY, TAB, Eth. \\
\hline 12 & 200795629 & & $\mathrm{~A} \& \mathrm{P}$ & Screw fixation & none & Excellent & None \\
\hline 13 & D.P & $\mathrm{CD}$ & & Plate & THA & $\mathrm{Bad}$ & PY, Eth, \\
\hline 14 & 200733764 & & $\mathrm{~A} \& \mathrm{P}$ & Screw fixation & none & Excellent & None \\
\hline 15 & 200043397 & & $\mathrm{~A}$ & Screw fixation & none & Good & None \\
\hline 16 & 200015124 & & $\mathrm{~A} \& \mathrm{P}$ & Screw fixation & none & Good & $\mathrm{HA}, \mathrm{CaBr}, \mathrm{CAR}$ \\
\hline 17 & 200807595 & $\mathrm{CD}$ & & Plate & none & Excellent & None \\
\hline 18 & 200512549 & & $\mathrm{~A}$ & Screw fixation & none & Excellent & TAB, Eth \\
\hline 19 & 200035155 & & $\mathrm{~A} \& \mathrm{P}$ & Screw fixation & MP-P & Good & DIAB, CAR, \\
\hline 20 & 200387037 & $\mathrm{AM}$ & & Plate & none & Good & $\mathrm{UR}, \mathrm{HA}$ \\
\hline 21 & 200891576 & $\mathrm{AM}$ & & Plate & none & Excellent & None \\
\hline 22 & 200581105 & $\mathrm{CD}$ & & Plate & RL, THA & $\mathrm{Bad}$ & DIAB, PY, CAR \\
\hline 23 & 200294234 & $\mathrm{AM}$ & & Plate & none & Excellent & None \\
\hline 24 & 200863478 & $\mathrm{CD}$ & & Plate & $\mathrm{RL}$ & $\mathrm{Bad}$ & $\mathrm{HA}, \mathrm{CAR}, \mathrm{CaPr}$. \\
\hline 25 & 200658464 & $\mathrm{AM}$ & & Plate & none & Excellent & None \\
\hline 26 & 200759991 & $\mathrm{CD}$ & & Plate & $\mathrm{RL}$ & $\mathrm{Bad}$ & DIAB, HA, CAR \\
\hline 27 & 200447299 & $\mathrm{AM}$ & & Plate & none & Excellent & none \\
\hline 28 & 200106964 & $\mathrm{CD}$ & & Screw \& THA & none & Excellent & HA, CAR, TAB \\
\hline 29 & 200051791 & $\mathrm{CD}$ & & Plate & RL, THA & Bad & none \\
\hline 30 & 200547546 & $\mathrm{CD}$ & & Plate & $\mathrm{RL}$ & $\mathrm{Bad}$ & PY, TAB, Eth \\
\hline 31 & 200891700 & $\mathrm{CD}$ & & Plate & RL, THA & $\mathrm{Bad}$ & HA, DIAB, UR \\
\hline 32 & 200845944 & $\mathrm{CD}$ & & Plate & RL, THA & $\mathrm{Bad}$ & HA, CAR, TAB \\
\hline 33 & 200230616 & $\mathrm{CD}$ & & Plate & $\mathrm{RL}$ & $\mathrm{Bad}$ & Died \\
\hline 34 & 200804852 & $\mathrm{CD}$ & & Plate & RL, THA & Bad & PY \\
\hline 35 & 200461282 & & $\mathrm{~A} \& \mathrm{P}$ & Screw fixation & none & Excellent & none \\
\hline 36 & 200571633 & & $\mathrm{~A} \& \mathrm{P}$ & Screw fixation & none & Excellent & none \\
\hline 37 & 200788467 & & $\mathrm{~A} \& \mathrm{P}$ & Screw fixation & none & Excellent & DIAB \\
\hline 38 & 200817938 & & $\mathrm{~A} \& \mathrm{P}$ & Screw fixation & none & Excellent & HA, Eth \\
\hline 39 & 200390989 & & $\mathrm{~A} \& \mathrm{P}$ & Screw + Plate & none & Moderate & $\mathrm{HA}, \mathrm{CAR}, \mathrm{CaBr}$ \\
\hline 40 & 200848526 & & $\mathrm{~A} \& \mathrm{P}$ & Screw fixtion & Pain-P & Moderate & PY \\
\hline 41 & 200896932 & $\mathrm{AM}$ & & Plate + Screw & none & Good & none \\
\hline 42 & 200452544 & & $\mathrm{~A} \& \mathrm{P}$ & Screw fixation & none & Excellent & none \\
\hline 43 & 200900371 & & $\mathrm{~A} \& \mathrm{P}$ & Screw fixation & none & Excellent & none \\
\hline 44 & 200893319 & & $\mathrm{~A} \& \mathrm{P}$ & Screw fixation & none & Excellent & none \\
\hline 45 & 200915747 & & $\mathrm{~A} \& \mathrm{P}$ & Plate and Screw & NonUnion-A & Moderate & PY, TAB \\
\hline 46 & 000131085 & & $\mathrm{~A} \& \mathrm{P}$ & Screw fixation & none & Excellent & none \\
\hline 47 & 200439538 & & $\mathrm{~A} \& \mathrm{P}$ & Screw fixation & none & Excellent & none \\
\hline 48 & 200225821 & & $\mathrm{~A} \& \mathrm{P}$ & Screw fixation & none & Excellent & none \\
\hline 49 & 200979108 & & $\mathrm{~A} \& \mathrm{P}$ & Screw fixation & MP-A & Excellent & none \\
\hline 50 & 200096011 & & $\mathrm{~A} \& \mathrm{P}$ & Screw fixation & none & Moderate & HA, DIAB, CAR -died \\
\hline 51 & 200220390 & & $\mathrm{~A} \& \mathrm{P}$ & Screw fixation & none & Moderate & none \\
\hline 52 & 200400789 & & $\mathrm{~A} \& \mathrm{P}$ & Screw fixation & none & Excellent & none \\
\hline 53 & 200960731 & & $\mathrm{~A}$ & Screw fixation & none & Excellent & none \\
\hline 54 & VDB-GF & & $\mathrm{A}$ & Screw fixation & MP-A & Good & DIAB, HA, REN \\
\hline
\end{tabular}

Figure 1. Patients demographics. AM: Anteromedial dislocation of the hip joint; CaBr: breast cancer CaPr: prostate cancer; CD: Central dislocation of the hip joint; Tox: consumption of drugs; A\&P: Anterior and posterior fracture of the pelvic ring; DVT: deep venous thrombosis; PY: psychiatric disorders; MP-A: malposition of the anterior column screw; CAR: cardiac failure; MP-P: malposition of the posterior SIG screw; HA: arterial hypertension; TAB: Tabaco abuse; Eth.: alcohol abuse; UI: urinary infection UR: prostatismREN: renal dialysis; TIA : transient ischemic accident. 
Follow-up was one year. The reasons for non-operative treatment were often the fragility of the patient, being "too sick to operate on", or refusal of the operative treatment because the patients could not understand the benefits of the operative fixation of their fractures. The mean age of our patient's cohort was 76 years $(62-94)$. The male to female ratio was 16 to 38 . In all cases, we noticed a sedentary lifestyle. We recorded a simple fall from standing height for most of the cases. Only in one case did we find a concomitant subtrochanteric fracture on the same site of the pelvic ring disruption. In the pelvic ring fracture group $(\mathrm{n}=$ 34), 32 cases received a retrograde screw fixation (Figure 2). In two patients, we performed an antegrade screw fixation of the anterior column. In 25 patients, the anterior column screw fixation was combined with a percutaneous sacroiliac joint fixation by one or two screws. In all cases, a $7.3 \mathrm{~mm}$ cannulated screw was used (De Puy-Synthes, Belgium). We placed all percutaneous screws under fluoroscopic control. In six bifocal (anterior and posterior pelvic ring fractures) cases with displaced pubic bone fracture, adducting the ipsilateral leg reduced the dislocated pubic bone fracture easily (Figure 2(b)). In the fracture dislocation group $(\mathrm{n}=20)$, the patients were more active. In half of the cases, the injury

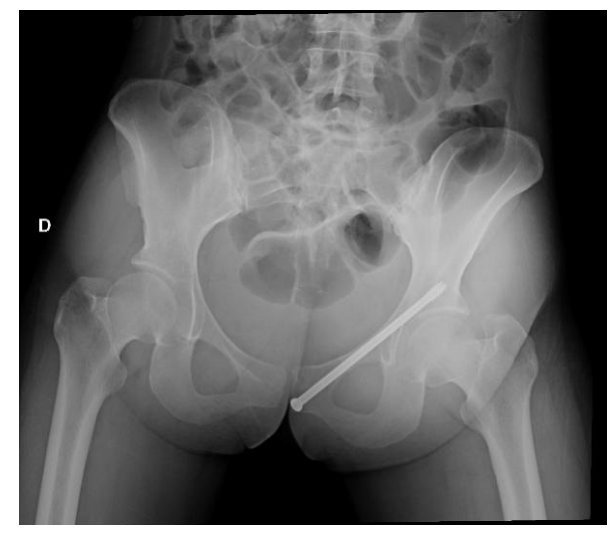

(a)
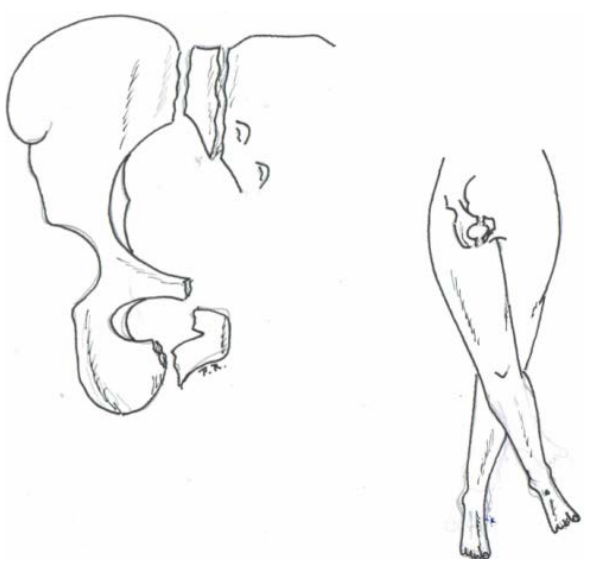

(b)

Figure 2. (a) Radiographs of a retrograde screw fixation of the anterior column; (b) Reducing an unstable pubic bone fracture by adducting the ipsilateral leg during surgery. 
was because of a moderate to high energy trauma. Road traffic accidents were the cause of injury for four patients, another two fell from a bicycle, and two fell from a sizeable height-the rest of these patients injured their hip because of a lateral fall from standing height. Eight patients presented with an anteromedialdislocated hip joint. The rest presented a pure central fracture dislocation of the acetabulum. All patients were offered a plate osteosynthesis via an extensive retroperitoneal approach [8]. We performed all retroperitoneal approaches with the help of an abdominal surgeon (F.M.). To stabilise the quadrilateral wall of the acetabulum, we used an infrapectineal plating technique [9]. As a buttress for the quadrilateral wall, we used an additional small fragment $\mathrm{T}$ plate (DePuy-Synthes, Dilbeek Belgium) 13 times and a straight 4.5 large fragment plate four times. These additional plates were bent more than $90^{\circ}$ and dynamically pushed against the quadrilateral wall in a reduced position. We secured these perpendicularly orientated plates under the long curved pelvic plate. We placed no screws in the quadrilateral bone plate, hence avoiding the hip joint (Figure 3). In four cases, we tried the "Matta plate", which has some exciting features. For the Matta plate, side plate is located at one-third of the plate length to buttress the quadrilateral bone plate. We did not succeed in the proper placement of this plate extension. Often, the plate turned away from the quadrilateral wall. Confronted with severe osteoporosis, we cabled the infrapectineal plate to the superior ramus of the pubic bone using $1 \mathrm{~mm}$ cables from DePuy-Synthes, Dilbeek-Belgium (Figure 3). We did not let the plate wander to the iliac wing because the bone is rather thin and preferred there, so where possible, we positioned the plate as close to the SIG as possible. Another possibility for strong anchoring bone screws in the pelvis is the iliac pillar [10], a bony thickening extending from the acetabulum to the iliac tubercle.

The iliac pillar provides adequate implant bone stock and is usually intact, even in geriatric patients with osteoporosis [9].

To reach the dense bone aside the sacroiliac joint, we had to dissect medial from the iliopsoas muscle and obturator nerve and lateral from the external iliac artery.

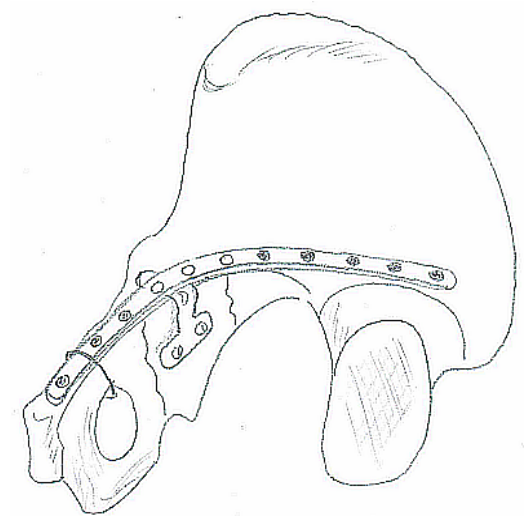

Figure 3. Infrapectineal plate fixating with a "spring" plate configuration to reduce the quadrilateral wall in a dynamic way together with cabling of the plate at its iliopubic portion. 
In cases of central dislocation of the hip joint, we used allografts from a donor femoral head to reinforce the central acetabular dome. The fixation technique was the same in both subgroups: anteromedial dislocated and central dislocated hip joints.

\section{Results}

Results were categorised as Excellent. no loss of reduction, no other complication, and return to previous functional level. Good: no loss of reduction, no other complications, loss of one level of functional recovery Moderate: no loss of reduction, one complication, loss of two levels of functional recovery.

Bad: Loss of reduction, one or more complication, loss of all four levels of functional recovery.

Functional levels: first level complete recovery, second level use of one crutch outdoors, third level only walking with help indoors, fourth level bedridden.

The visual analogue scale (VAS) for pain improved dramatically after percutaneous screw fixation of the pelvic ring. In the preoperative stage, the VAS score was 9 on a scale of 10 , with a score of 10 meaning extreme pain sensation and 0 meaning no pain at all. The day after surgery, the VAS dropped to 6 , and two weeks after surgery, the pain was graded as a 3. After surgery, all patients were CT scanned to verify the positioning of their pelvic ring screws. We encountered four patients with malposition screws out of the 32 patients with pelvic ring fractures we performed the procedure on. Two sacroiliac screws (SIG) and two anterior column screws (Figure 4 and Figure 5). Only one SIG screw needed to be changed because the distance between the tip of the screw and the arteria iliaca communis was dangerously close. In the two cases with a missed SIG screw, the fixation was done with the patient in the supine position. In the 25 cases of iliosacral screw fixation, we did not encounter any loosening of the screws. After surgery of the pelvic ring, no weight bearing was allowed for two months. All pelvic ring fractures, save for one, healed within three months. In one case, screw fixation of the anterior pubic branch was insufficient. This patient became symptomatic while walking (predominantly pain) and needed bone grafting of his non-union site nine months after surgery in combination with plate fixation of the anterior pubic branch. After one year, ten patients could not walk independently and were mostly wheelchair ridden. 27 patients were rated excellent, 9 patients good and 8 were moderated at one year. Two patients died after their follow-up of one year of causes not related to their injury. In the subgroup of anteromedial dislocation of the hip, we had no complications, and all fractures healed well. However, in the subgroup of central dislocation of the hip joint, we managed to retain the femoral head in the anatomical position in two cases. In all other cases, we witnessed the gradual displacement of the femoral head. Often, the indentation of the superomedial dome was beyond repair. Especially in fractures with the seagull sign, the femoral head tended to slip into the superomedial cavity of the acetabular dome. We saw no infection in this series. 


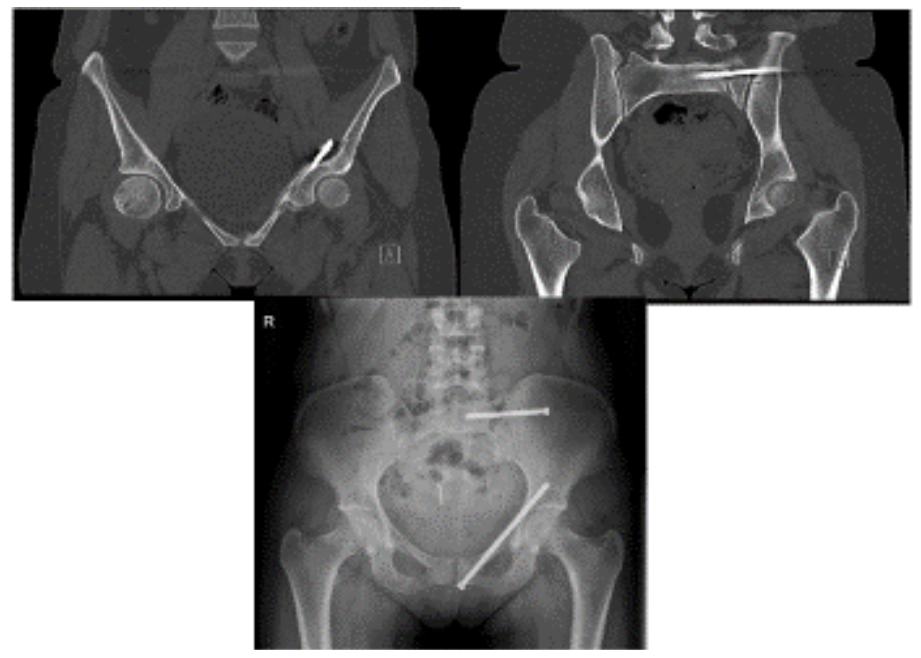

Figure 4. Female 73 years old, with a mal placed retrograde pubic screw. She had no complains and refused further surgery.

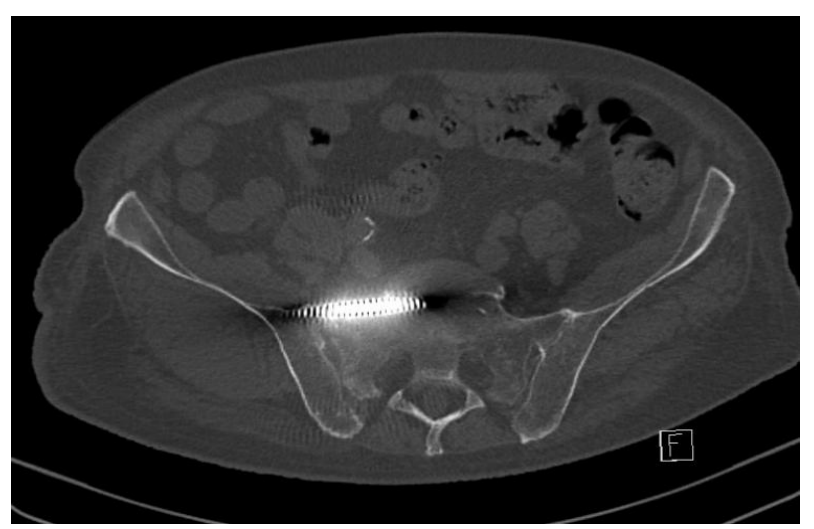

Figure 5. Anterior placement of a sacroiliac screw. This screw was placed with the patient in a supine position. In the supine position, it's difficult to approach the sacroiliac joint as posterior as necessary to target S1 (black line).

\section{Discussion}

From 1970-1997, the incidence of osteoporotic fractures of the pelvis increased by $460 \%$ [1]. The impact of these fractures is substantial and underestimated [2] [3] [4]. With no treatment, slow healing of these fractures is reported, with a mortality rate at one year of $20 \%$ and a return to the same functional level at one year of only $16 \%$ [5] [6] [11]. In pelvic ring fractures, the posterior fracture of the sacral wing is often not seen on plain radiographs, making CT evaluation necessary for a complete diagnosis. Ricci and Gerich [7] showed through a theoretical analysis using an elaborated finite element model of a pelvis that the stresses at the sacral wing increase dramatically after interruption of the pubic rami. The work of Ricci and Gerich can explain why we often see fatigue fractures in the back of the pelvic ring together with fractures of the pubic area. Pain is predominant after pelvic ring fractures, making nursing with simple bed-seat transfers difficult. 
Other studies have confirmed the high prevalence of posterior pelvic ring disruption in association with a fracture of both branches of the pubic bone [7] [12]. The treatment options are, in most cases, nonsurgical. However, most patients experience prolonged pain, often leading to impaired function and confusion.

We did not use the classification system of Rommens PM. Used [10] [13], though, for the fragility fractures of the pelvis. This system classifies the pelvic fractures in the elderly in four groups based on increasing instability of the pelvis. Each group has three subcategories making this classification system rather difficult to use.

Recently, there has been a shift from exclusive non-operative treatment to a more pragmatic and nuanced approach [2]. Especially for posterior pelvic disruption, surgical treatment modalities are numerous, ranging from minimally invasive trans-iliac bridging plate osteosynthesis [14] [15] to the elegant technique of trans-iliac internal fixator [16] and complex triangular osteosynthesis and lumbopelvic fixation [8]. For the fixation of anterior pelvic ring fractures, we prefer a retrograde-placed transpubic screw, as described by Rommens PM. [12]. In this study, pain and discomfort together with a displaced fracture in the front (ilio-pubic or ischio-pubic branches) or both fractures in the front or in the back was an indication for surgery. In our study, we wanted to determine the safest corridor for retrograde screw fixation of the anterior column. Therefore, we loaded plastic bone models of the pelvis (Synbone AG Zizers, Switzerland) with metal markers and placed several screws in a retrograde way, bridging the whole anterior column. Positioning the fluoroscopic C-arm in an obturator position with the fluoroscopic beam perpendicularly orientated to the plane of the acetabular gave the broadest possible view of the safest corridor that would span the whole anterior column (Figure 6). We were satisfied with this technique of retrograde medullary pubic bone fixation. Indeed, it was found to be minimally invasive and for most cases gave an excellent anchoring of the screws, even in osteopenic bone. The patients were satisfied with the drop in pain after surgery, which they graded as severe after the injury. The mean VAS index dropped from 9 to 6 immediately after surgery and then to 3 after six weeks. Immediately after surgery, bed seat transfers were possible, increasing the nursing comfort of these patients. Because the corridor of the anterior column was too narrow in six of our cases, we were not able to cross the acetabulum. In these cases, the screw seat rested entirely in the superior pubic ramus. In four cases, we noticed a mal placement of the screws, specifically two SIG and two anterior column screws. In the two malposition SIG screws, these were placed with the patient in the supine position. For anaesthetic reasons, it was not possible to turn these patients in a prone position. With obese patients, it is hard to approach the posterior pelvic wing from the front (Figure 5). In the pelvic ring fracture group at one year, eight patients could not walk independently outdoors and were classified as moderate as end result. The rest resumed their daily activities as before. All patients mentioned slight discomfort in the lower back region. It was not clear if 
Retrograde Anterior Column Screw

Placement; Which way to go?

The aim of this study is to analyze the safest route and fluoroscopy position using plastic phantoms equipped with metal markers.
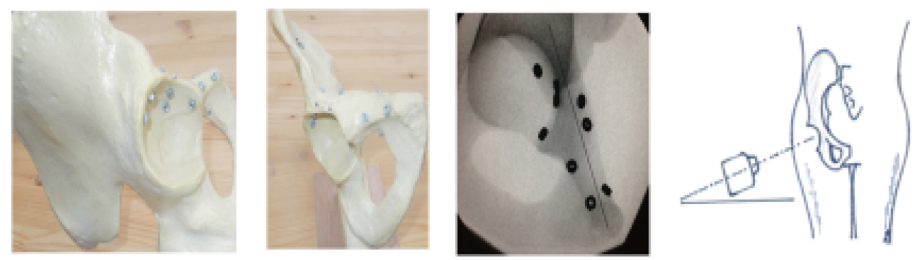

With the patient supine, we found the Out-Inlet view with oblique position of the beamer, $30^{\circ}$ exorotation and orthogonal to the plane of the acetabulum (fluoroscopy beamer cephalically orientated, $30^{\circ}$ in the horizontal plane) the safest position for percutaneous retrograde screw placement of the anterior column of the pelvis.

Figure 6. Loading a plastic phantom of a hemi-pelvis with metal beads, we could verify the save corridor for retrograde screw fixation of the anterior column.

this was because of the iliosacral screw or because of pre-existing degenerating arthritis of the lumbar spine. Four patients complained about the prominence of their screws in front of the pubic bone. This slight discomfort did not hinder their ambulatory function. We did remove the malpositioned screws in two pelvic fracture patients. The acetabular fracture group patients $(\mathrm{n}=20)$ were more active compared with the previous fracture group. In half of the cases, the mechanism of injury was because of moderate to high energy trauma. Road traffic accidents were the cause of injury for four patients, another two fell from a bicycle, and two fell from a sizeable height-the rest of these patients injured their hip because of a lateral fall from standing height. We discerned two different fracture patterns, each with different outcomes. The first group of eight patients had an anteromedial fracture dislocation of their hip through the acetabulum. The second group of twelve patients had a complete central dislocated hip joint. These patients in the two subgroups benefited an open reduction and internal fixation of the acetabulum via an extensive retroperitoneal approach. All central fractures of the acetabulum had injured the weight-bearing dome (seagull sign) with concomitant damage to the femoral head. In the central dislocated hip fracture group, we tried to reduce the displaced quadrilateral wall with bent small fragment $\mathrm{T}$ plates and 3.5 DCP plates (Figure 7).

In an attempt not to violate the hip joint, we avoided any screw fixation of the quadrilateral plate. We used allografts to fill the indented superomedial part of the weight-bearing area of the acetabular dome. Because of osteoporosis, in most cases, we reinforced the "pubic" part of the plate with one or two cables of a 1 mm diameter (DePuy-Synthes, Dilbeek, Belgium). In the central dislocated fracture group eight out of nine fractures were displaced secondarily. One patient 
with a history of severe alcohol abuse developed a secondary congruency of his hip joint and could ambulate pain free with a walking frame. This patient was satisfied despite the severely impaired mobility of the hip joint and refused further surgery (Figure 8). In the same central dislocated group, six patients received a mean delay of one year for the THA. We were pleased to see that the retroperitoneal approach did not hinder the placement of a total hip prosthesis (Figure 9). Also during hip replacement surgery, the infrapectineal pelvic plate and screws did not hinder the placement of the hip prosthesis. We performed a retrograde screw fixation of the anterior column in the same session as the THA in one case (Figure 10). In another case with severe destruction of the acetabulum, beyond repair, a retrograde pubic screw was anchored in the supra-acetabular region. In this position, the smooth shaft of the screw was abutting the femoral head in a "reduced" position. With this technique, the patient doesn't need to stay in traction. With this temporary tamponing of the femoral head in a reduced position, one can buy time to perform the THA on a better moment (Figure 11).

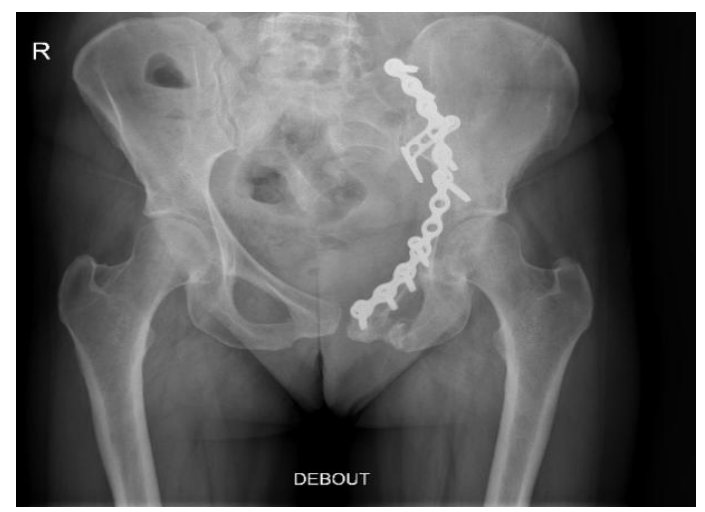

Figure 7. Use of a bent small fragment T-plate to stabilize the quadrilateral plate. This plate is secured under a long pelvic ring plate.
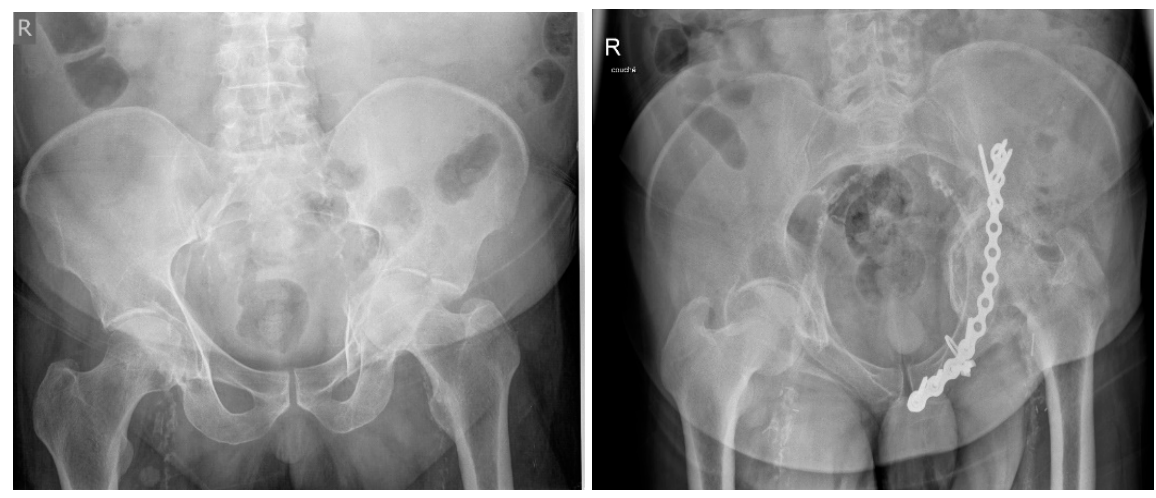

Figure 8. Failed osteosynthesis after central dislocation of the hip joint with severe depression of the acetabular dome, so called sea gull sign. Patient was happy with the development of a secondary congruency of his hip joint and refused further surgery despite severe limitation of the hip mobility. 
In fixing the anteromedial fracture dislocated hip joint $(n=8)$, we encountered no complications. At a mean time of one year, all these patients could walk pain free. For security reasons, half of these patients still used their walking frame one year after surgery.

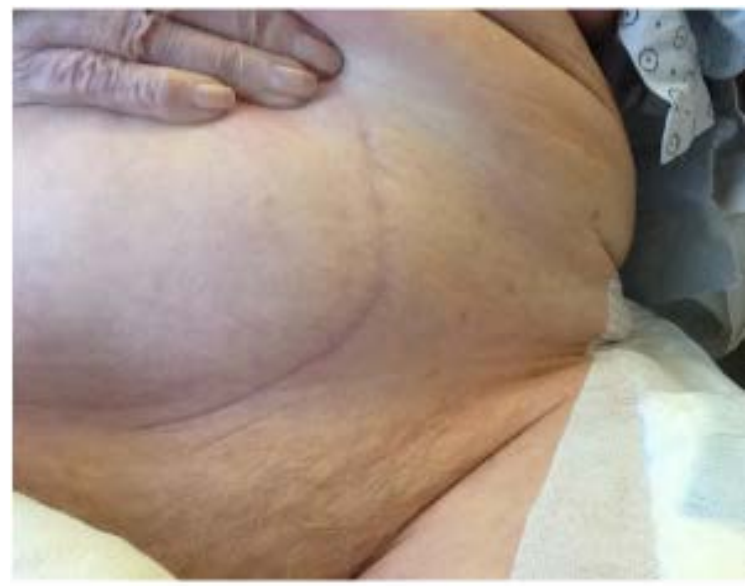

Figure 9. Healed incision for retroperitoneal approach, used for internal fixation of fracture dislocation of the hip joint.

Male, 90 Yrs old, simple fall

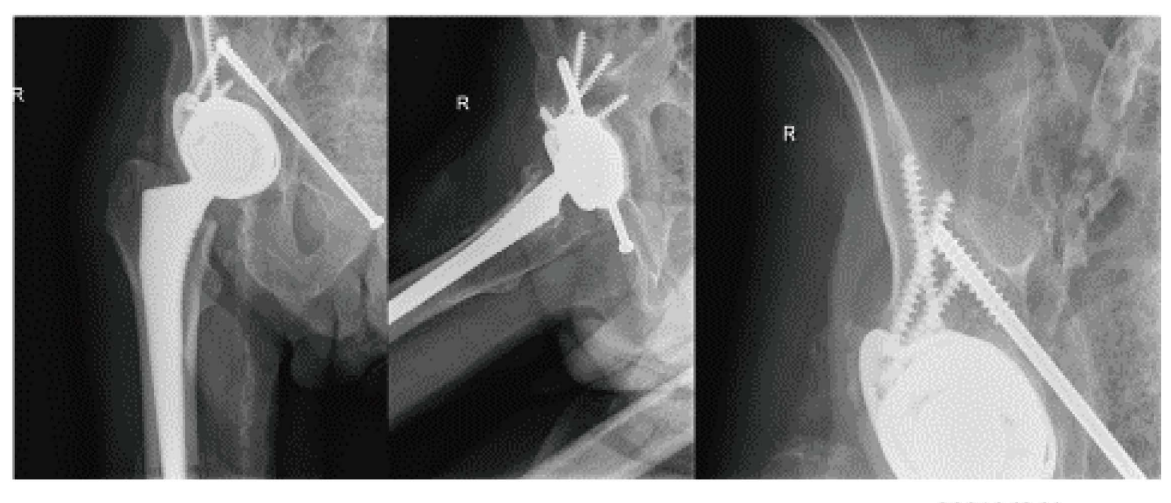

200106964

Figure 10. Percutaneous and retrograde screw fixation of the anterior column and THA in the same session.

91 Years old, fall out of bed

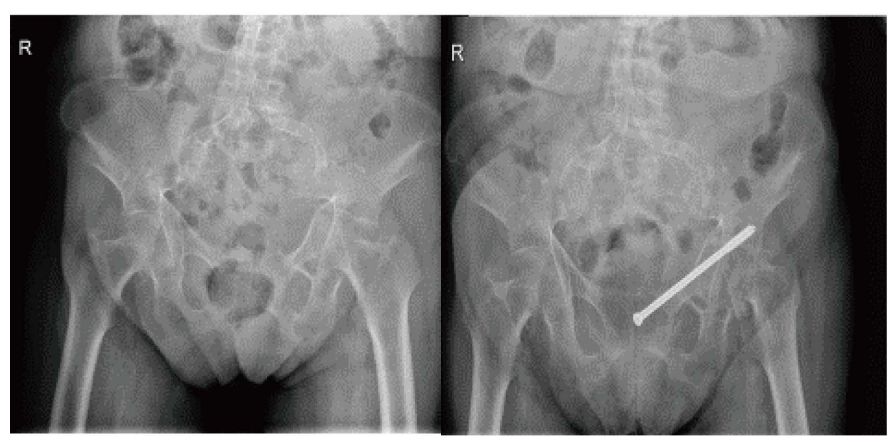

(a) 


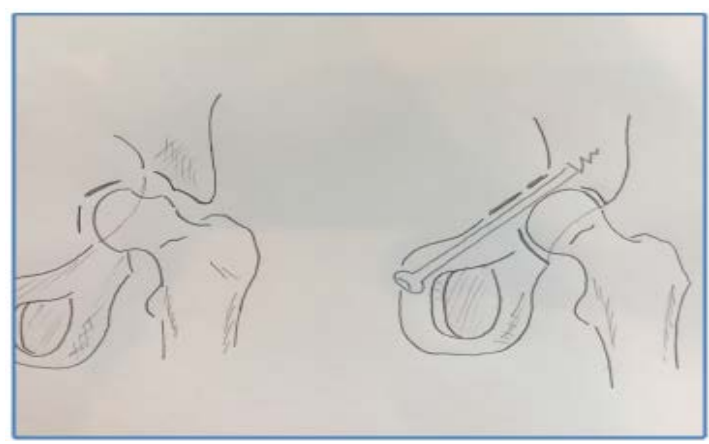

(b)

Figure 11. Severe central dislocation in a frail patient. Traction failed to relieve her pain. (a) A percutaneous, retrograde, anterior column screw was positioned intra-articular of the acetabulum. The shaft of screw abutting against the femoral head, keeping the hip joint reduced.

(b) Draft, showing the essence of the technique.

\section{Conclusion}

A major drawback of the current study is the small number of patients. Also, the lack of a control group makes the conclusions somewhat weaker. However, based on our experiences, we believe that the retrograde medullary screw fixation of the anterior column under fluoroscopic guidance is a safe and efficient way to stabilise the pelvis. For the proper anchoring of retrograde-placed screws, crossing the acetabulum is mandatory. We feel confident that $3 \mathrm{D}$ navigation is not always necessary for this purpose. In the acetabular fracture group, the central dislocated hip joint performed poorly after osteosynthesis. Restoring the bone defect in the acetabular dome with allografts and osteosynthesis seems pointless. We no longer advocate osteosynthesis in this fracture type. Acute or delayed THA seems to give better results. The retroperitoneal approach is instrumental in fixing these acetabular fractures, and this approach did not compromise the later THA.

\section{Conflicts of Interest}

The authors declare no conflicts of interest regarding the publication of this paper.

\section{References}

[1] Kannus, P., et al. (2000) Epidemiology of Osteoporotic Pelvic Fractures in Elderly People in Finland: Sharp Increase in 1970-1997 and Alarming Projections for the New Millennium. Osteoporosis International, 11, 443-448. https://doi.org/10.1007/s001980070112

[2] Raschke, M. and Fuchs, Th. (2007) Iliosacral Screw Fixation with Cement Augmentation. In: Rommens, P.M. and Hofmann, A., Eds., Fragility Fractures of the Pelvis, Springer International Publishing, Berlin, 139-144. https://doi.org/10.1007/978-3-319-66572-6_12

[3] Scheyerer, M.J., et al. (2012) Detection of Posterior Pelvic Injuries in Fractures of the Pubic Rami. Injury, 43, 1326-1329. https://doi.org/10.1016/j.injury.2012.05.016 
[4] Ayoub, M.A., et al. (2016) Standalone Percutaneous Transiliac Plating of Vertically Unstable Sacral Fractures: Outcomes, Complications, and Recommendations. European Spine Journal, 25, 1153-1162. https://doi.org/10.1007/s00586-015-3976-0

[5] Hockertz, Th. (2007) Bridging Plate Osteosynthesis. In: Rommens, P.M. and Hofmann, A., Eds., Fragility Fractures of the Pelvis, Springer International Publishing, Berlin, 157-164. https://doi.org/10.1007/978-3-319-66572-6_14

[6] Salasek, et al. (2015) Minimally Invasive Stabilization of Posterior Pelvic Ring Injuries with a Transiliac Internal Fixator and Two Iliosacral Screws: Comparison of Outcome. Acta Chirurgiae Orthopaedicae et Traumatologiae Cechoslovaca, 82, 41-47.

[7] Pierre-Louis, R., et al. (2018) Finite Element Analysis of the Pelvis Including Gait Muscles Forces: An Investigation into the Effect of Rami Fractures on Load Transmission. Journal of Experimental Orthopedics, 5, 33. https://doi.org/10.1186/s40634-018-0151-7

[8] Eddyb, S. (2016) Approach According to Jalaguier, PhD N 97 Surgical Interest in the Treatment of an Abdominal Plastron in the Adults. PhD Defended the 30-05-2016, University of Cadi Ayyad, Medical Faculty, Marrakech, Maroc.

[9] White, J., et al. (2013) Quadrilateral Plate Fractures of the Acetabulum: An Update. Injury-International Journal of the Care of the Injured, 44, 159-167. https://doi.org/10.1016/j.injury.2012.10.010

[10] Kim, W.Y., Lee, S.W., Kim, K.W., Kwon, S.Y. and Choi, Y.H. (2018) Minimally Invasive Surgical Treatment Using "Iliac Pillar" Screw for Isolated Iliac Wing Fractures in Geriatric Patients: A New Challenge. European Journal of Trauma and Emergency Surgery, 45, 213-219. https://doi.org/10.1007/s00068-018-1046-0

[11] Cameron, I.D., Kurrle, S., Klenk, J., Kleiner, A., Heinrich, S., König, H.H. and Becker, C. (2010) Excess Mortality after Pelvic Fractures in Institutionalized Older People. Osteoporosis International, 21, 1835-1839. https://doi.org/10.1007/s00198-009-1154-0

[12] Rommens, P.M., et al. (2007) Retrograde Transpubic Screw Fixation. In: Rommens, P.M. and Hofmann, A., Eds., Fragility Fractures of the Pelvis, Springer International Publishing, Berlin, 211-223. https://doi.org/10.1007/978-3-319-66572-6_19

[13] Dietz, S.O., Hofmann, A. and Rommens, P.M. (2015) Haemorrhage in Fragility Fractures of the Pelvis. European Journal of Trauma and Emergency Surgery, 41, 363-367. https://doi.org/10.1007/s00068-014-0452-1

[14] Schildhauer, T.A., et al. (2007) Bridging Triangular Osteosynthesis and Lumbopelvic Fixation. In: Rommens, P.M. and Hofmann, A., Eds., Fragility Fractures of the Pelvis, Springer International Publishing, Berlin, 175-189.

https://doi.org/10.1007/978-3-319-66572-6_16

[15] Eckhardt, H., et al. (2017) Good Functional Outcome in Patients Suffering Fragility Fractures of the Pelvis Treated with Percutaneous Screw Stabilization Assessment of Complications and Factors Influencing Failure. Injury-International Journal of the Care of the Injured, 48, 2717-2723. https://doi.org/10.1016/j.injury.2017.11.002

[16] Osterhoff, G., Scheyerer, M.J., Fritz, Y., et al. (2014) Comparing the Predictive Value of the Pelvic Ring Injury Classification Systems by Tile and by Young and Burgess. Injury, 45, 742-747. https://doi.org/10.1016/j.injury.2013.12.003 